\title{
The nature of complex ice flow in Shirase Glacier catchment, East Antarctica
}

\author{
Frank PATTYN, ${ }^{1}$ Renji NARUSE ${ }^{2}$ \\ ${ }^{1}$ Department of Geography, Vrije Universiteit Brussel, Pleinlaan 2, B-1050 Brussels, Belgium \\ E-mail:fpattyn@vub.ac.be \\ ${ }^{2}$ Institute of Low Temperature Science, Hokkaido University, Sapporo 060-0819, Japan
}

\begin{abstract}
The transition of inland to complex ice flow is investigated in the downstream area of Shirase Glacier catchment, East Antarctica. The $250 \mathrm{~km}$ long Mizuho Triangulation Chain (MTC; Naruse, 1978), $230 \mathrm{~km}$ upstream of the grounding line of Shirase Glacier, is re-analyzed by a force-balance analysis, in combination with balance-velocity estimates. Numerical model experiments were carried out with a two-dimensional thermomechanical higher-order ice-sheet model along a central flowline extending from the ice divide (Dome Fuji) to the grounding line of Shirase Glacier, passing through the MTC. Results show that complex flow originates near the MTC, where longitudinal normal stresses and normal drag in particular play a decisive role in the force balance. The fast-flow area, however, is geologically controlled and confined to the "bottleneck" or ice-flow convergence area, a few tens of kilometres upstream of the grounding line. In between the MTC and the grounding zone, longitudinal normal stress and basal sliding are dominant features of the ice-flow regime.
\end{abstract}

\section{INTRODUGTION}

The Antarctic ice sheet is primarily drained by large outlet glaciers and ice streams which play a decisive role in the dynamic behaviour of the ice sheet with changing climate. Shirase Glacier (Fig. 1) is one of these fast-flowing glaciers, characterized by surface velocities of $>2500 \mathrm{~m} \mathrm{a}^{-1}$ near the calving front (Fujii, 1981). A recent analysis of the surface velocity field obtained from European Remote-sensing Satellite (ERS) interferometry and an associated force-balance analysis of the grounding zone of Shirase Glacier revealed that, despite high driving stresses, $>90 \%$ of the ice velocity in that area is due to basal sliding. Furthermore, the effect of normal drag, a major component in the balance of forces of an ice mass, is limited to a narrow zone of $10-20 \mathrm{~km}$ upstream of the grounding line (Pattyn and Derauw, 2002). This contrasts with most other large Antarctic outlet glaciers and ice streams, such as the Siple Coast ice streams, where driving stresses are low and the "fast-flow" area is relatively large.

Even though the fast-flow zone of Shirase Glacier seems limited to the grounding zone, it is expected that ice flow in a larger part of the downstream Shirase Glacier catchment area is more complex than previously thought. Complex ice flow denotes here a mixture of ice-sheet flow (where deformation is basically governed by simple shear) and ice-stream/ shelf flow (where deformation is mainly governed by normal stresses and vertical shear is negligible). Evidence obtained from balance-velocity estimates suggests that each major Antarctic drainage basin is fed by complex systems of tributaries that penetrate hundreds of kilometres from the grounding line into the interior of the ice sheet (Bamber and others, 2000). The Shirase Glacier catchment area exhibits such finger-like pattern as well (Fig. 1). In view of these findings we will (i) investigate whether complex ice flow penetrates far upstream in the catchment area, and (ii) try to disentangle the nature of this complex ice flow. We therefore re-analyzed the Mizuho Triangulation Chain (MTC; Naruse, 1978), 230 km up-

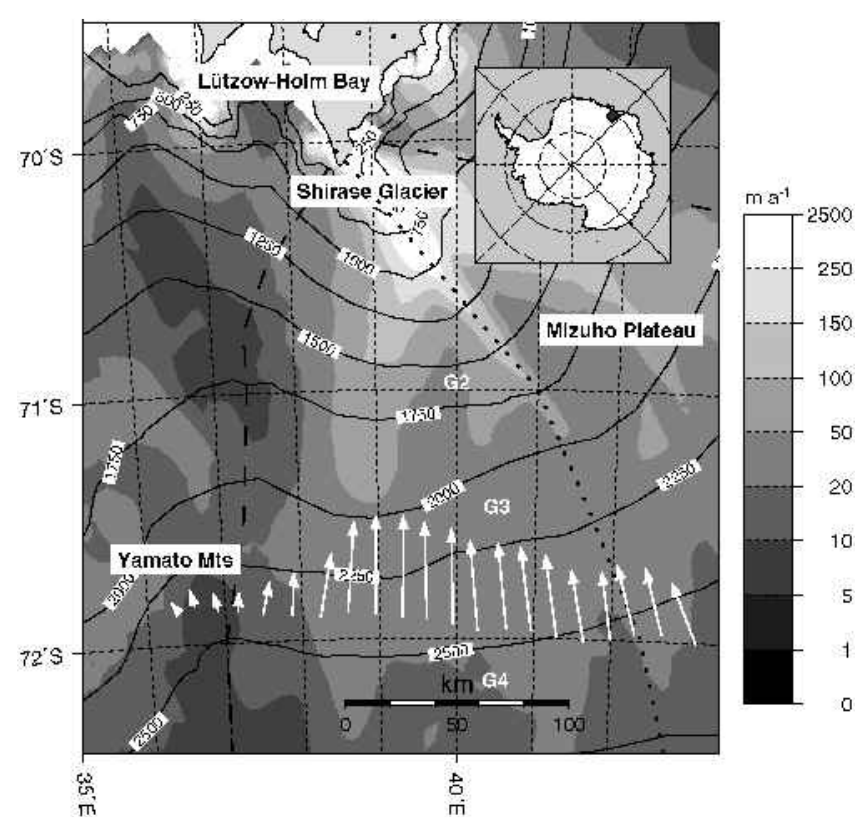

Fig. 1. Map of the Shirase Glacier catchment, Dronning Maud Land, East Antarctica. Arrowes denote velocity measurements derived from the Mizuho Triangulation Chain (MTC), where the maximum surface velocity equals $21 \mathrm{ma}^{-1}$. The dotted line is the central flowline; the dashed line delimits the catchment area. Balance velocities are plotted as background. The grounding line corresponds roughly to the coastline. 


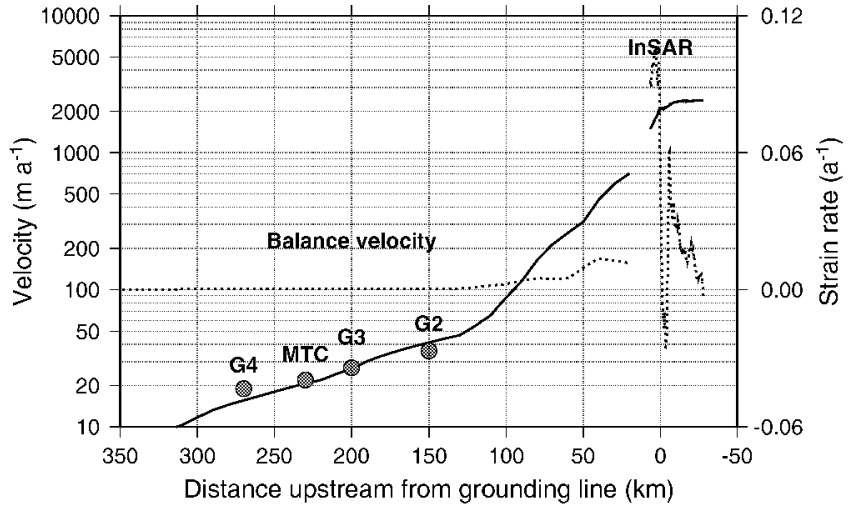

Fig. 2. Longitudinal profiles of velocity (solid line) and normal strain rate (dotted line) along the central flowline of Shirase Glacier. Data upstream from the grounding line are based on balance-velocity estimates. Data near the grounding line are derived from ERS SAR interferometry (InSAR; Pattyn and Derauw, 2002). G2, G3, G4 and MTC are field measurements of surface velocity by stake method. Note the logarithmic scale for the velocity only.

stream from the grounding line, using the force-balance method, and we performed numerical modelling experiments along the central flowline of the catchment area with a higherorder thermomechanical ice-sheet model.

\section{BAGKGROUND}

\section{Surface flow observations}

Although ice speed at the grounding line of Shirase Glacier exceeds $2000 \mathrm{~m} \mathrm{a}^{-1}$, normal strain rates $\dot{\varepsilon}_{x x}$ are of the order of $0.1 \mathrm{a}^{-1}$, which is very high for an Antarctic outlet glacier (Fig. 2; Pattyn and Derauw, 2002). Further inland, ice velocity is significantly lower. For instance, at G2 (Figs 1 and 2), $150 \mathrm{~km}$ upstream of the grounding line, the surface speed is $<40 \mathrm{~m} \mathrm{a}^{-1}$ (Nishio and others, 1989). These high strain rates close to the grounding line can be explained by the large convergence of the ice flow in this region, where the grounding zone becomes a "bottleneck" for the flow of ice from the interior and ice is drained into a subglacial trench. The convergence pattern is observed in ERS synthetic aperture radar (SAR) images, where the flow bands are clearly visible (Fig. 3). Compared to other major East Antarctic outlet glaciers, such as Lambert Glacier or Jutulstraumen, the grounding-line flux gate of Shirase Glacier is relatively small: a width of $8 \mathrm{~km}$ and an ice thickness of $900 \mathrm{~m}$. A recent mass-balance analysis at the grounding line revealed that the amount of mass that flows through the flux gate at the grounding line is more or less in equilibrium with the total amount of accumulated ice in the catchment area, although a slight negative imbalance exists (Pattyn and Derauw, 2002). A mass-budget analysis by Rignot and Thomas (2002) confirms these equilibrium conditions. Thus, the high ice-flow speed of Shirase Glacier is necessary to maintain the flux in balance with the upstream mass input.

However, repeated field observations in the Shirase Glacier catchment point to a significant thinning of the ice sheet. This thinning was calculated from differencing the emergence (submergence) velocity measured at stake markers with surface accumulation. Thinning of the ice-sheet surface was estimated at $0.5-0.8 \mathrm{~m} \mathrm{a}^{-1}$ along the $72^{\circ} \mathrm{S}$ paral-

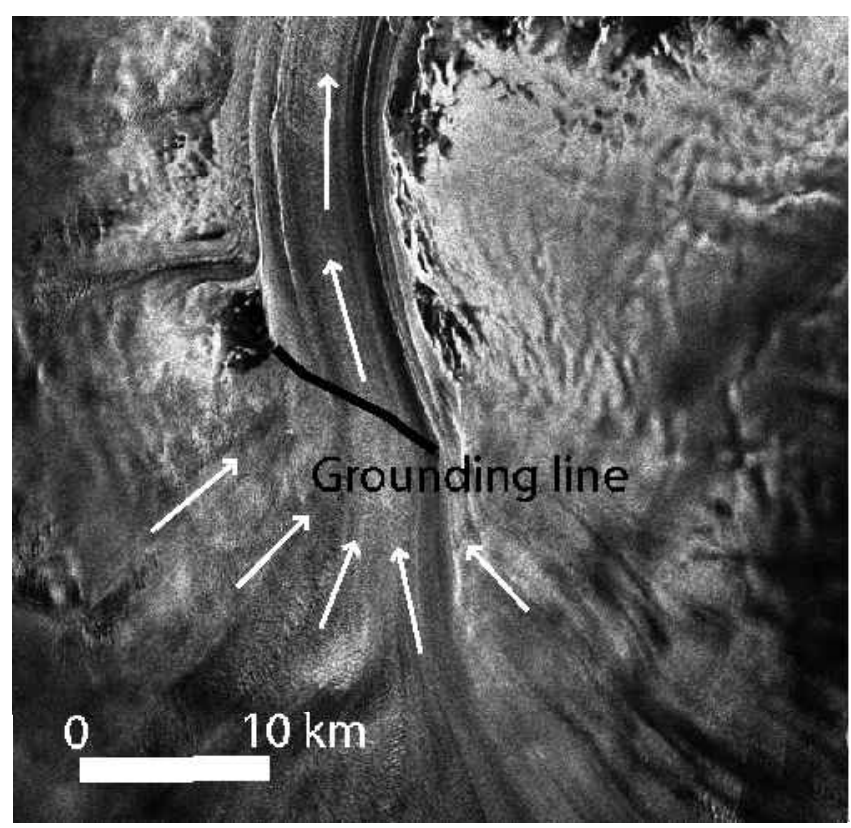

Fig. 3. ERS SAR amplitude image of the grounding zone of Shirase Glacier. The convergence of the flowlines is clearly seen and shows that the grounding line forms a "bottleneck" for the ice flow from the interior. Arrows display the direction of the ice flow.

lel (Naruse, 1979), to $2.5 \mathrm{~m} \mathrm{a}^{-1}$ further downstream at G2 (Nishio and others, 1989), values that are at least an order of magnitude higher than those obtained from mass-budget considerations (Pattyn and Derauw, 2002). The thinning seems due to large submergence velocities that cannot be compensated for by the amount of snow accumulation. An analysis by Mae and Naruse (1978) and Mae (1979) stipulated that the origin of this thinning is caused by basal sliding, which was estimated as high as (if not higher than) the deformational velocity along the $72^{\circ} \mathrm{S}$ parallel.

\section{Modelling efforts}

Several modelling initiatives tried to shed light on the dynamic behaviour of Shirase Glacier, with respect to the observed thinning of the ice sheet. Numerical model experiments by Fujita and others (1991) revealed that the ice sheet on Mizuho Plateau was relatively stable even if major model parameters were changed. This robust behaviour was also confirmed by Pattyn and Decleir (1995). A possible mechanism responsible for increased basal sliding resulting in important thinning of the ice sheet is due to thermal oscillations (Pattyn, 1996). Similar mechanisms were also explored by MacAyeal (1992), Payne (1995) and Hindmarsh and Le Meur (2001). The basis of such thermal oscillations is that creep enhancement due to increased heat dissipation is counteracted by advection of cold ice due to the thinner ice sheet. The ice sheet slows down and enters a build-up phase, until the ice is thick enough and basal temperatures reach the pressure-melting point again so that a new rapid phase can set in. The periodicity of these cycles is approximately 3000-4000years. Such modelled oscillations were only observed in the downstream area of Shirase Glacier, and disappeared gradually towards the inland plateau. Whether such a mechanism applies to Shirase Glacier and its catchment area remains questionable and difficult to verify. 


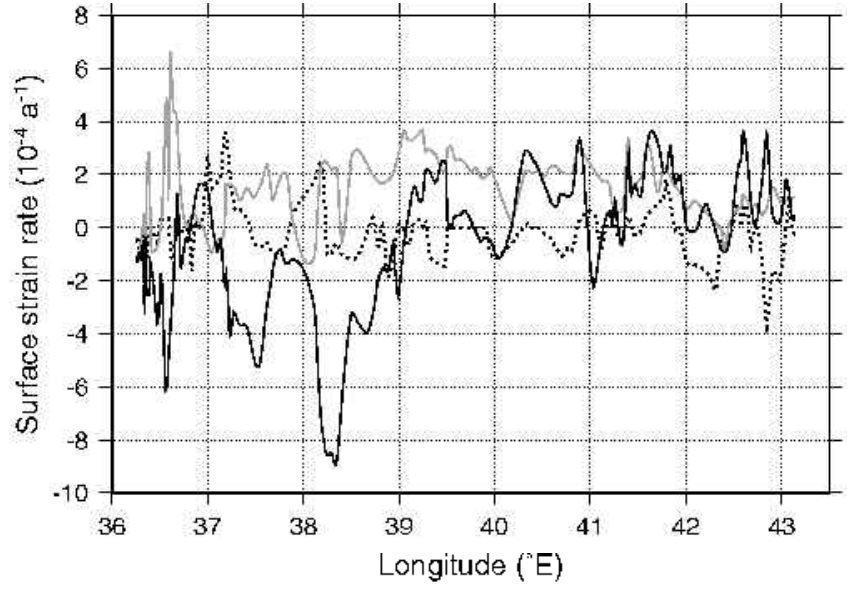

Fig. 4. Surface strain rates determined from MTC (Naruse, 1978): $\dot{\varepsilon}_{x x}$ (gray line), $\dot{\varepsilon}_{y y}$ (dotted line) and $\dot{\varepsilon}_{x y}$ (black line). The $x$ axis is taken in the direction of the ice flow (parallel to the $40^{\circ}$ Emeridian).

\section{RE-ANALYSIS OF MTG}

\section{Surface strain rate and velocity}

The MTG is a $250 \mathrm{~km}$ long survey network, composed of 164 stations stretched along the $72^{\circ} \mathrm{S}$ parallel, between the Yamato Mountains in the west and the centre of the catchment at $43^{\circ} \mathrm{E}$ (Fig. 1). It was surveyed in 1969 and resurveyed 4 years later. Naruse (1978) analyzed the survey result of the triangulation net and estimated the horizontal and vertical velocities of the ice surface and strain rates at the surface using standard methods as presented in Jaeger (1969). Mean errors in horizontal and vertical velocity are 0.68 and $0.2 \mathrm{~m} \mathrm{a}^{-1}$, respectively (Naruse, 1979). Calculated values for $\dot{\varepsilon}_{x x}, \dot{\varepsilon}_{y y}$ and $\dot{\varepsilon}_{x y}$ are displayed in Figure 4. Normal strain rates in the direction of the flow $\dot{\varepsilon}_{x x}$ are positive along most of the chain. High longitudinal normal strain rates are found close to the Yamato Mountains $\left(36-37^{\circ} \mathrm{E}\right)$. High (negative) shear strain rates occur between $38^{\circ}$ and $39^{\circ} \mathrm{E}$ and might indicate a shear band between the divide and stream-flow. The local ice divide, between the Shirase Glacier catchment and the adjacent drainage basin, is situated at $37^{\circ} \mathrm{E}$. At this ice divide, transverse normal strain rates $\dot{\varepsilon}_{y y}$ are distinctly positive as well.

\section{Balance velocities}

Additional data for the present analysis are (i) surface accumulation from a recent mass-balance assessment of the Antarctic ice sheet (Vaughan and others, 1999), (ii) surface topography based on satellite altimetry (Liu and others, 1999), and (iii) ice thickness distribution (BEDMAP; Ly the and others, 2001). All datasets are on a $5 \mathrm{~km}$ grid resolution. Despite the large time lapse between the acquisition of the MTC data and the satellite observations of Liu and others (1999), both surface topographic datasets are in agreement. They only differ by a constant offset, so that calculated surface slopes will not be affected. Using these datasets, balance fluxes and velocities are calculated by the method proposed by Budd and Warner (1996). Therefore, the digital elevation model is smoothed over a horizontal distance of $25 \mathrm{~km}$ (or $\pm 10 H$ ) to remove short-wavelength undulations (Bamber and others, 2000). Balance fluxes are obtained by integrating the accumulation of the whole catchment area in the direc- tion of the flow. Balance fluxes divided by the local ice thickness result in so-called balance velocities, and equal the vertical mean horizontal velocity, assuming the ice sheet is in steady state. A map of balance velocities in the Shirase Glacier catchment displays a complicated pattern of ice flow in the downstream area (Fig. 1), where a number of fingerlike patterns merge near the grounding line. These patterns seem to propagate quite far upstream. The central flowline of the catchment area coincides with one of these major balance-velocity features.

Balance-velocity estimates are compared with observed velocities along the central flowline of Shirase Glacier catchment (Fig. 2). Observed velocities at G4 are slightly higher than balance velocities compared to those further downstream (e.g. at G2). This is because (i) balance velocities should not equal per se surface velocities, and (ii) G2-G4 are not exactly along the central flowline. Nevertheless, velocity gradients (normal strain rates) along the flowline show an agreement between observed and modelled (balance) velocities. With the exception of the grounding zone, normal strain rates increase to a value of $0.01 \mathrm{a}^{-1}$, indicating a modest acceleration of the ice flow. This acceleration culminates in $\dot{\varepsilon}_{x x} \approx 0.1 \mathrm{a}^{-1}$ close to the grounding line, as determined from ERS SAR interferometry (Pattyn and Derauw, 2002). Immediately downstream of the grounding line, ice compression occurs $\left(\dot{\varepsilon}_{x x}<0\right)$ due to horizontal shearing at both sides of the floating ice tongue (Pattyn and Derauw, 2002).

\section{Force-balance calculation}

Following the notation of Van der Veen and Whillans (1989), the force balance in three dimensions, integrated from the surface to the base of the ice mass, reads

$$
\begin{gathered}
\tau_{\mathrm{b} x}=\tau_{\mathrm{d} x}+\frac{\partial}{\partial x} \int_{b}^{s} R_{x x} \mathrm{~d} z+\frac{\partial}{\partial y} \int_{b}^{s} R_{x y} \mathrm{~d} z, \\
\tau_{\mathrm{b} y}=\tau_{\mathrm{d} y}+\frac{\partial}{\partial x} \int_{b}^{s} R_{x y} \mathrm{~d} z+\frac{\partial}{\partial y} \int_{b}^{s} R_{y y} \mathrm{~d} z,
\end{gathered}
$$

where $R_{x x}$ and $R_{y y}$ are the resistive normal stress components, and $R_{x y}$ the resistive shear stress component. $s$ and $b$ denote the surface and the bottom of the ice mass, respectively. The $x$ axis is taken in the direction of the ice flow. Resistive stresses are related to the stress components by $R_{i j}=\tau_{i j}+\delta_{i j} \rho g(s-z)$ (Van der Veen and Whillans, 1989), where $\delta_{i j}$ is the Kronecker delta, $\rho$ is the ice density $\left(910 \mathrm{~kg} \mathrm{~m}^{-3}\right)$ and $g$ is the gravitational acceleration $\left(9.81 \mathrm{~m} \mathrm{~s}^{-2}\right)$. The driving stress is defined as $\tau_{\mathrm{d}}=-\rho g H \nabla s$, where $H$ is the ice thickness and $\nabla s$ the surface slope. The basal drag $\tau_{\mathrm{b}}$ equals the sum of all resistive stresses at the base:

$$
\tau_{\mathrm{b} i}=R_{i z}(b)-R_{x i}(b) \frac{\partial b}{\partial x}-R_{y i}(b) \frac{\partial b}{\partial y} \quad \text { for } i=x, y
$$

where $R_{x z}$ and $R_{y z}$ are the vertical resistive shear stress components, determined by numerical integration of Equa- 
tions (1) and (2). Resistive stresses are related to strain rates by

$$
\begin{aligned}
& R_{x x}=B \dot{\varepsilon}_{\mathrm{e}}^{\frac{1-n}{n}}\left(2 \dot{\varepsilon}_{x x}+\dot{\varepsilon}_{y y}\right), \\
& R_{y y}=B \dot{\varepsilon}_{\mathrm{e}}^{\frac{1-n}{n}}\left(2 \dot{\varepsilon}_{y y}+\dot{\varepsilon}_{x x}\right), \\
& R_{x y}=B \dot{\varepsilon}_{\mathrm{e}}^{\frac{1-n}{n}} \dot{\varepsilon}_{x y},
\end{aligned}
$$

where $n=3$ is Glen's flow-law exponent. Similar expressions are found for $R_{x z}$ and $R_{y z}$. In turn, the effective strain rate $\dot{\varepsilon}_{\mathrm{e}}$ and the strain-rate components $\dot{\varepsilon}_{i j}$ are defined as

$$
\begin{aligned}
\dot{\varepsilon}_{\mathrm{e}}^{2} & =\dot{\varepsilon}_{x x}^{2}+\dot{\varepsilon}_{y y}^{2}+\dot{\varepsilon}_{x x} \dot{\varepsilon}_{y y}+\dot{\varepsilon}_{x y}^{2}+\dot{\varepsilon}_{x z}^{2}+\dot{\varepsilon}_{y z}^{2}, \\
\dot{\varepsilon}_{x x} & =\frac{1}{2}\left(\dot{\varepsilon}_{1}+\dot{\varepsilon}_{2}\right)+\frac{1}{2}\left(\dot{\varepsilon}_{1}-\dot{\varepsilon}_{2}\right) \cos (2 \theta), \\
\dot{\varepsilon}_{y y} & =\frac{1}{2}\left(\dot{\varepsilon}_{1}+\dot{\varepsilon}_{2}\right)+\frac{1}{2}\left(\dot{\varepsilon}_{1}-\dot{\varepsilon}_{2}\right) \cos (2 \theta+\pi), \\
\dot{\varepsilon}_{x y} & =-\left(\dot{\varepsilon}_{1}-\dot{\varepsilon}_{2}\right) \sin (2 \theta),
\end{aligned}
$$

where $\dot{\varepsilon}_{1}$ and $\dot{\varepsilon}_{2}$ are the principal strain rates derived from the triangulation chain, and $\theta$ is the direction of the principal strain $\dot{\varepsilon}_{1}$ (maximum extension). $B$ is a function of the vertical temperature profile and obeys an Arrhenius relationship. Since the temperature profile in this area is not known, we adopted a steady-state temperature profile obtained from numerical ice-sheet model experiments (see below). Only one vertical temperature profile was used for the numerical integration along the whole length of the MTC. This assumption is valid, since surface topography and ice thickness are more or less constant along the MTG. The temperature profile takes into account vertical diffusion and advection, horizontal advection and frictional heating at the base, given the present ice sheet is in steady state (Pattyn, 2000). Due to the lack of borehole measurements along the MTC, this probably results in a more realistic estimate than any analytic solution.

Three major assumptions were made in the forcebalance calculations. The first assumption is that strain rates are kept constant with depth equal to the measured surface value (cf. Høydal, 1996). However, the associated stresses will vary with depth as the flow parameter $B$ and the effective strain rate $\dot{\varepsilon}_{\mathrm{e}}$ are depth-dependent. Stress gradients in the $y$ direction (perpendicular to the flow) are calculated along the triangulation chain. However, as the MTC is stretched into one direction, stress gradients in the along-flow direction cannot be determined from the MTC strain data. Therefore, our second assumption is that the effective strain rate is more or less constant in the along-flow direction, i.e. $\partial \dot{\varepsilon}_{\mathrm{e}} / \partial x \sim 0$, and the third assumption is that strain rates in the along-flow direction can be replaced by balance-velocity gradients. Although balance velocities do not equal measured surface velocities, their gradients seem in agreement (Fig. 2). Moreover, Bamber and others (2000) have shown that balance velocities provide a good description of the spatial pattern of horizontal ice flow (determined from SAR interferometry) in the interior of Antarctica. Making use of the above assumptions, along-flow stress gradients are thus approximated by

$$
\begin{aligned}
& \frac{\partial R_{x x}}{\partial x} \approx B \dot{\varepsilon}_{\mathrm{e}}^{\frac{1-n}{n}}\left(2 \frac{\partial^{2} u_{\mathrm{b}}}{\partial x^{2}}+\frac{\partial^{2} v_{\mathrm{b}}}{\partial x \partial y}\right), \\
& \frac{\partial R_{x y}}{\partial x} \approx \frac{1}{2} B \frac{1-n}{\dot{\varepsilon}_{\mathrm{e}}^{n}}\left(\frac{\partial^{2} v_{\mathrm{b}}}{\partial x^{2}}+\frac{\partial^{2} u_{\mathrm{b}}}{\partial x \partial y}\right),
\end{aligned}
$$

where $u_{\mathrm{b}}$ and $v_{\mathrm{b}}$ are the components of the balance velocity in the $x$ and $y$ direction, respectively. They are determined
Table 1. Estimation of errors in the force-balance calculations

\begin{tabular}{ccc}
\hline & Mean value & $\sigma$ \\
\hline$s(\mathrm{~m})$ & 2500 & 5 \\
$\nabla s$ & $5 \times 10^{-3}$ & $1.41 \times 10^{-3}(*)$ \\
$H(\mathrm{~m})$ & 2000 & 100 \\
$u\left(\mathrm{~m} \mathrm{a}^{-1}\right)$ & 15 & 0.68 \\
$\dot{\varepsilon}\left(\mathrm{a}^{-1}\right)$ & $5 \times 10^{-4}$ & $3.24 \times 10^{-4}(*)$ \\
$B(\mathrm{kPa})$ & $1 \times 10^{-2}$ & $3.24 \times 10^{-4}(*)$ \\
$\tau_{\mathrm{d}}(\mathrm{kPa})$ & 500 & 100 \\
$\tau_{\mathrm{b}}(\mathrm{kPa})$ & 90 & $25(*)$ \\
& 40 & $8(*)$ \\
& 110 & $21(*)$
\end{tabular}

Notes: Besides a mean value for the strain rates, we added a "high value" of $\dot{\varepsilon}=10^{-2}$, for which appropriate error estimates are determined on the basal drag. (*) indicates that errors are determined after error propagation (Bevington and Robinson, 1992).

using the direction vector of the flow based on the surface topography data.

Equations (1) and (2) are integrated numerically from the surface of the glacier to an arbitrary height $z$, starting with the surface stress field, and using 100 equidistant layers in the vertical. At each layer, horizontal stress gradients are calculated, as well as the flow parameter $B$ based on the assumed vertical temperature profile. From the vertical shear stress gradient, the shear stress components $R_{x z}$ and $R_{y z}$ are determined at the next layer. Once the integration reaches the base of the ice mass, the basal drag is determined from Equation (3) (Van der Veen and Whillans, 1989). Surface slopes, necessary for the determination of the driving stress, were calculated over a horizontal distance of $5 \mathrm{~km}$, which is approximately two ice thicknesses, since high-frequency noise in the surface slopes might affect the force-balance calculations. A quality assessment of the force budget is presented in Table 1. Using mean values for parameters and observations, errors are determined from the theory on error propagation (Bevington and Robinson, 1992). For instance, the error in driving stress $\tau_{\mathrm{d}}$ is given by

$$
\begin{aligned}
\sigma_{\tau_{\mathrm{d}}} & =\left[\left(\frac{\partial \tau_{\mathrm{d}}}{\partial H}\right)^{2} \sigma_{\mathrm{H}}^{2}+\left(\frac{\partial \tau_{\mathrm{d}}}{\partial \nabla s}\right)^{2} \sigma_{\nabla s}^{2}\right]^{\frac{1}{2}} \\
& =\left[(\rho g \nabla s)^{2} \sigma_{\mathrm{H}}^{2}+(\rho g H)^{2} \sigma_{\nabla s}^{2}\right]^{\frac{1}{2}} .
\end{aligned}
$$

Similar expressions are found for all other calculated variables. Errors in surface slopes, determined from the mean error in surface elevation and the distance over which gradients were calculated, are overestimated, as the accuracy of the elevation data is probably higher where surface slopes are small (Liu and others, 1999). Although errors in strain rates are relatively large, the propagated errors in driving stress and basal drag are acceptable. The largest error is associated with the driving stress $\left(25 \%\right.$ of $\left.\tau_{\mathrm{d}}\right)$. Errors in basal drag are generally $<20 \%$ (Table 1 ).

Force-balance computation using a one-shot integration of the force-balance equations from the surface to the base is inherently dangerous. When all boundary conditions are specified at the surface, the boundary-value problem becomes ill-posed and unstable; small changes in surface velocities might correspond to disproportionally large velocity and stress changes at depth (Bahr and others, 1994). This ill-posed condition depends on the horizontal 


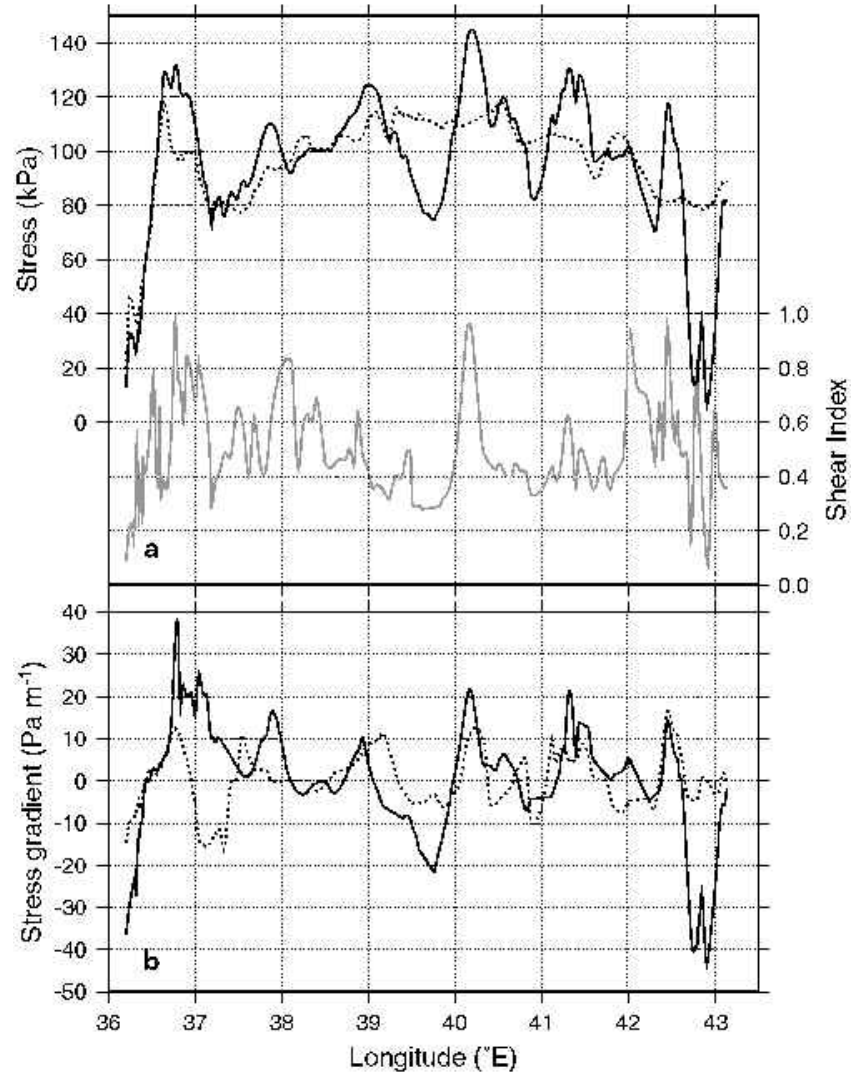

Fig. 5. (a) Driving stress $\tau_{\mathrm{d} x}$ (dotted line), calculated basal drag $\tau_{\mathrm{b} x}$ (black line) and shear index $S I$ (gray line) in the direction of the ice flow along the MTC. (b) Surface-normal drag $\partial R_{x x} / \partial x$ (solid line) and surface lateral drag $\partial R_{x y} / \partial y$ (dotted line).

resolution applied in the computation, and limits velocity calculations at the bed to wavelengths on the order of one ice thickness or greater (Bahr and others, 1994). Therefore, the effect of horizontal discretization of surface slopes in the force balance was investigated. Calculating surface slopes over distances of more than two ice thicknesses (i.e. 10,20 and $40 \mathrm{~km}$ ) results in stress variations at depth which differ by $<5 \%$. This low sensitivity is due to the generally flat surface topography in this area, so that smoothing out surface slopes over larger distances does not significantly alter the force-balance results. Also ice-thickness variations do not play a major role as $H$ is fairly constant along the MTC profile. The force-balance computation seems therefore rather robust.

\section{Basal drag and shear index}

Figure 5 shows the basal drag and driving stress in the direction of flow along the MTC. The driving stress $\tau_{\mathrm{d} x}$ is relatively constant along the whole length of the MTC, at 80$110 \mathrm{kPa}$. The basal drag $\tau_{\mathrm{b} x}$ oscillates around the profile of the driving stress and oscillations are not all synchronous with the driving-stress profile. Lowest values for the basal drag are found close to the Yamato Mountains in the west and in the central part of the catchment area, between $42^{\circ}$ and $43^{\circ} \mathrm{E}$, on the eastern side of the MTG. Highest values are found in the central part of the MTC, but even here the basal drag oscillates between 70 and $150 \mathrm{kPa}$. High peaks in the basal drag might refer to so-called pinning points which resist the flow. As we did not find a relation between basal drag, driving stress and the bedrock profile (ice thickness remains fairly constant along the MTG), these zones of higher basal drag might indicate so-called "sticky spots" or zones where the ice sheet is frozen to the bed, since they are not associated with a clearly identified bedrock bump.

Basic components of the stress-field anomaly are the normal drag $\partial R_{x x} / \partial x$ and the lateral drag $\partial R_{x y} / \partial y$ (Fig. $5 b)$. Normal drag is highly negative on both sides of the MTC, i.e. near the Yamato Mountains (compressive ice flow) as well as near the centre of the catchment area, where the low basal drag indicates stream-flow. Lateral drag is more or less constant along the MTC, and even the large shear strain rates between $38^{\circ}$ and $39^{\circ} \mathrm{E}$ (Fig. 4) are not reflected in the lateral drag profile. In most cases, normal and lateral drag are in phase, which amplifies their effect on the basal drag. In zones where they are out of phase (e.g. at $37^{\circ} \mathrm{E}$ ) they hardly affect the basal drag profile.

To characterize the type of ice flow along the MTC, we introduced the "shear index" SI, based on the depth-dependent flank-flow index of Marshall and Cuffey (2000). The SI differentiates between ice flow driven by simple shear and ice flow driven by pure shear. Since this is a depth-independent parameter, simple shear is represented by the basal shear stress $R_{x z}(b)$ (as shear stresses are concentrated at the base of the ice mass), while pure shear is represented by the depth-averaged value of the resistive normal stress $\overline{R_{x x}}$. The shear index is defined as

$$
\mathrm{SI}=\frac{\left|R_{x z}(b)\right|}{\left|R_{x z}(b)\right|+\left|\overline{R_{x x}}\right|},
$$

so that a value of $\mathrm{SI}=1$ denotes simple shear, while for $\mathrm{SI}=0$, pure shear dominates. The shear index for the MTC is also displayed in Figure 5. Lowest values of SI are found at the ice divide between the Shirase Glacier catchment and the adjacent basin in the west; the highest values generally correspond to high basal drag. SI values are lowest on either side of the MTC, coinciding with areas where normal drag plays an important role in reducing the basal drag. The SI profile is quite heterogeneous over the central part of the MTC, characterized by generally low values (0.4-0.5). Some distinct peaks of high SI are distinguished, notably near $40^{\circ}$ and $42^{\circ} \mathrm{E}$.

The force-balance method also allows for a determination of the basal velocity, based on the vertical integration of strain rates (Fig. 6). Calculated basal velocity is lowest on the western side of the MTC, and highest sliding velocities coincide with regions of highest surface velocity and the eastern side of the MTC, near the centre of the catchment area. Outside these zones, calculated basal velocity is equal to or less than the deformational velocity.

\section{NUMERIGAL MODELLING}

As mentioned before, the force-balance method has one inherent deficiency, i.e. short-wavelength features develop at depth because of the ill-posed boundary-value problem (Bahr and others, 1994). In reality, these features exist but are filtered by the glacier when they are transmitted towards the surface. In the inverse calculation, however, these features have no physical meaning (Mayer and Huybrechts, 1999). A more robust way of investigating the stress field in ice masses is by forward (prognostic) instead of inverse modelling. The ice mass is then investigated in response to atmospheric conditions at the surface, i.e. surface mass 


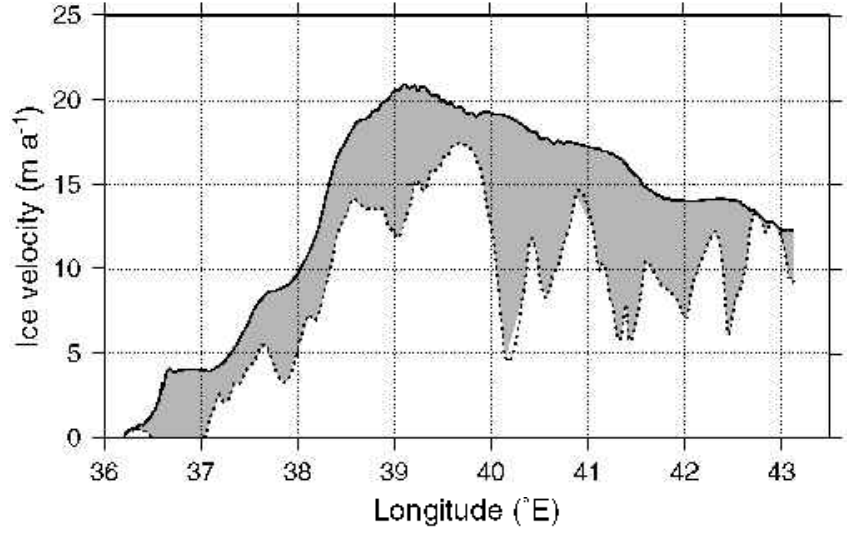

Fig. 6. Measured surface velocity $u_{\mathrm{s}}$ (solid line) and calculated basal velocity $u(z=b)$ (dotted line) along the $M T C$. The shaded area represents the amount of deformation velocity.

balance and temperature. Surface velocity becomes a calculated quantity instead of a measured quantity used as input to the model.

Model experiments along the central flowline were carried out with a high-resolution time-dependent two-dimensional thermomechanical flowline model, which takes into account all relevant stresses (i.e. both shear and longitudinal normal stress gradients) and is solved on a finite-difference grid with $\Delta x=10 \mathrm{~km}$. The model experiments are described in Pattyn (2000). A detailed description of the higher-order numerical flow model is presented in Pattyn (2002). The stress equilibrium used in this model is similar to Equation (1). Transverse normal stresses $\tau_{y y}^{\prime}$ are also taken into account, albeit in an implicit way by taking care of the width variations of the flow field perpendicular to the central flowline (Pattyn, 2000). Basal sliding is introduced in the model in the form of a Weertman-type sliding law (e.g. Van der Veen, 1987)

$$
u_{\mathrm{b}}=A_{\mathrm{b}} \frac{\tau_{\mathrm{b}}^{3}}{N}
$$

where $A_{\mathrm{b}}$ is the sliding constant $\left(2 \times 10^{-7} \mathrm{~m}^{5} \mathrm{~N}^{-2} \mathrm{a}^{-1}\right)$ and $N$ is the effective normal pressure proportional to the height of the glacier's surface above buoyancy, i.e. $N=\rho g H+\rho_{\mathrm{s}} g b$, where $\rho_{\mathrm{s}}$ is the sea-water density $\left(1028 \mathrm{~kg} \mathrm{~m}^{-3}\right)$. At the seaward edge the ice sheet transforms into a floating ice tongue, hence grounding-line dynamics are properly accounted for. The model is numerically solved on a fixed grid in space and time, with 30 layers in the vertical. Starting from present climatic input (surface accumulation and temperature), the model was run to steady state, reached after approximately $200 \mathrm{kyr}$.

Model results point to the importance of longitudinal normal stresses in the area near and downstream of the MTC (Fig. 7). The longitudinal normal stress deviator $\tau_{x x}^{\prime}$, related to the longitudinal normal resistive stress by $R_{x x}=2 \tau_{x x}^{\prime}+\tau_{y y}^{\prime}$ (cf. Equation (4) and Van der Veen and Whillans, 1989), is generally $>100 \mathrm{kPa}$, hence of the same order of magnitude as basal shear and driving stress, as corroborated by the results of the force-balance calculations on the MTC. The longitudinal normal stress deviator reaches a maximum in the region $50-250 \mathrm{~km}$ upstream of the grounding line (Fig. 7). At the grounding line it again reaches a maximum value. High values of $\tau_{x x}^{\prime}$ do not occur at the surface, but at a height halfway up the ice sheet, due to the

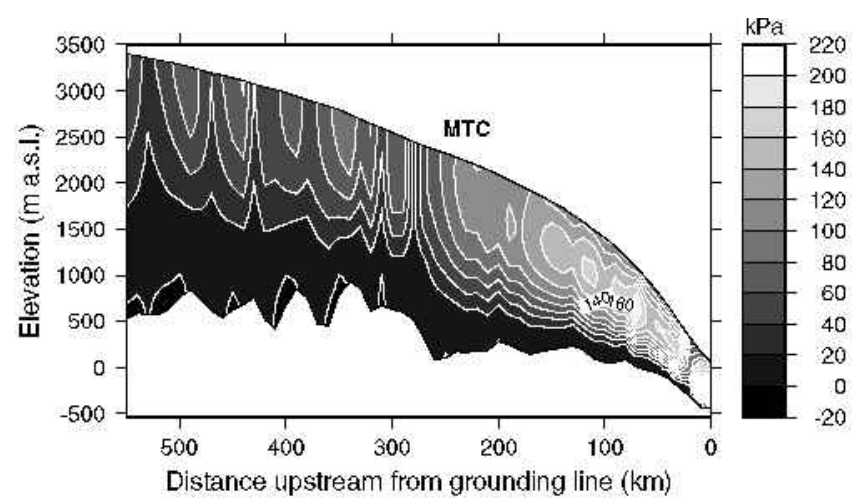

Fig. 7. Modelled longitudinal normal stress deviator $\tau_{x x}^{\prime}$ along the central flowline of Shirase Glacier catchment.

thermomechanical coupling of the velocity field to the temperature field (Pattyn, 2000). At certain places within the ice mass, the longitudinal normal stress deviator is twice as large as the basal shear stress, the latter not higher than $130 \mathrm{kPa}$ along the whole flowline (not shown). The model results also indicate that a few kilometres upstream of the grounding line the longitudinal normal stress deviator locally decreases to increase again at the grounding line, where the ice sheet becomes afloat. This behaviour results in an important normal drag, close to the grounding line, and confirms the observation from the ERS SAR velocity data (Pattyn and Derauw, 2002). A marked increase in longitudinal normal stress occurs a few kilometres upstream of the MTC, which indicates the importance of normal drag in the force balance of the MTC as well.

\section{DISGUSSION}

From the above analyses it is clear that longitudinal normal stresses play an important role in the force balance of the downstream area of the Shirase Glacier catchment. While most of the velocity increase is situated in a small area close to the grounding line (the so-called "bottleneck"), model results demonstrate that longitudinal normal stresses play a dominant role in the whole downstream catchment area, i.e. between the MTC and the grounding line. Upstream of the MTC, ice flow is dominated by shear stress. The eastern part of the MTC (in the centre of the catchment) is characterized by an increased importance of normal drag in the force balance, and the basal drag pattern clearly shows areas with reduced basal drag in between "sticky spots". This dominance of longitudinal normal stresses (and their gradients) in the force balance of the Shirase Glacier catchment is in contrast to the dynamic conditions of the Siple Coast ice streams, where side drag seems a dominant factor (Van der Veen and Whillans, 1989; Whillans and Van der Veen, 1997; Raymond, 2000).

Variations in the basal drag pattern along the MTC indicate a possible channelling of the ice flow. This channelling can be due to basal topography or a variation in ice and/or sliding viscosity Hindmarsh (2001). The lack of clear channel patterns in the bedrock topography favours the latter explanation. However, bedrock elevation data are rather sparse in this area and mostly concentrated east of the central flowline through the catchment area and along the MTC. Balance velocities display a channelled flow, forming a finger-like pattern upstream of the grounding line (Fig. 1). 


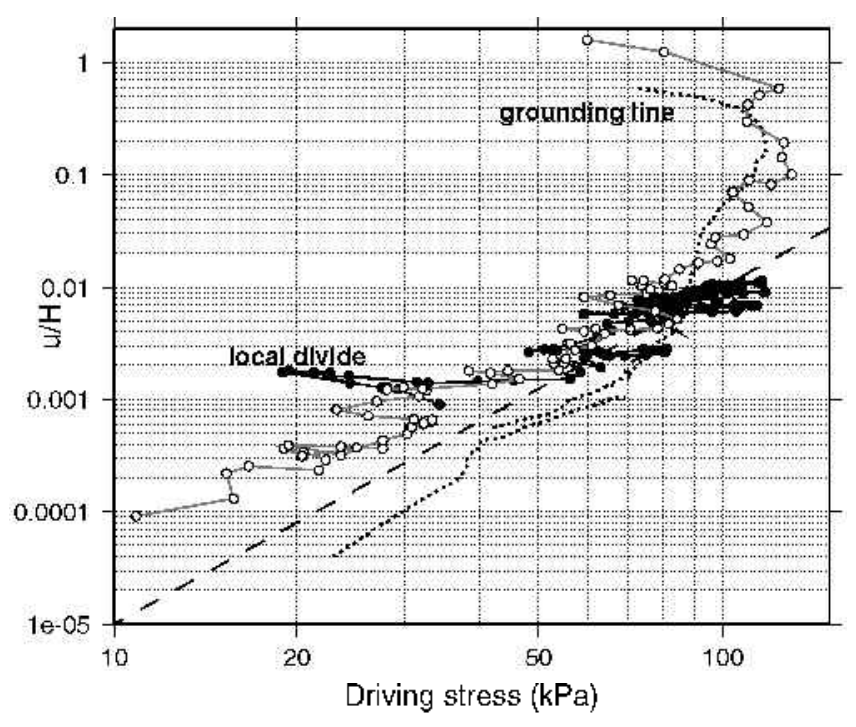

Fig. 8. Scaled velocity $u / H$ vs driving stress $\tau_{\mathrm{d}}$ for $M T C$ (solid black line); modelled $u / H$ vs modelled $\tau_{\mathrm{d}}$ along central flowline (dotted line); scaled balance velocity $u_{\mathrm{b}} / H$ vs observed $\tau_{\mathrm{d}}$ along the same flowline (greyline). The dashed line corresponds to lamellar flow with Glen's flow-law exponent $n=3$.

The channel flow seems limited to the area of converging ice flow, i.e. the area downstream of the MTC. A recent analysis of dual-frequency, multi-polarization-plane radar surveys in this area shows the presence of strong anisotropies, induced by anisotropic permittivity contrasts (personal communication from K. Matsuoka, 2002). This implies that ice fabrics show a stronger single maximum as the ice flows towards the lower reaches, which corroborates the possibility of channel flow. As a result of this channelling, a feedback between heating, temperature and viscosity may cause unstable or symmetry-breaking behaviour (Hindmarsh, 2001), and lead to a "limit-cycle" process as described in Pattyn (1996).

The "onset" of an ice stream is defined as the point of transition from inland to ice-stream flow, or the transition from shear-stress driven (lamellar) ice-sheet flow to more complex and/or fast ice flow. One way to differentiate between different flow types is a logarithmic plot of the scaled velocity $u / H$ vs the driving stress $\tau_{\mathrm{d}}$. For lamellar flow, this relation is, according to Glen's flow law, given by $u / H=A \tau_{\mathrm{d}}^{n}$, and plotted as a straight line with slope $n=3$ in Figure 8. We added three different datasets to Figure 8, i.e. (i) the observed MTC data (measured surface velocity vs driving stress), (ii) the steady-state modelled data(vertical mean horizontal velocity vs modelled driving stress along the central flowline), and (iii) the balance-velocity data (balance velocity vs the measured driving stress along the central flowline). All data lines start near the lower-left corner of the plot, i.e. the divide region characterized by low driving stresses and slow flow. Most of the data points are aligned with the line of lamellar flow, indicating a more or less ice-sheet type of flow. The central part of the MTC is clustered along the lamellar-flow line, but deviates to a large extent near the ice divide on the western side of the MTC (Fig. 8), as divide flow is dominant here. Both datasets along the central flowline deviate from lamellar flow between the crossing with the MTC and the grounding line. This deviation is most pronounced for the modelled ice flow, and starts from the MTG in the downstream direction. For this region, driving stresses are more or less constant with increasing ice speed, which indicates not only that ice deformation is governed by simple shear, but that basal sliding (and longitudinal stretching) becomes more prominent. Only near the grounding line is an inverse relation between driving stress and flow speed noticed: a typical feature of ice streams, i.e. that all deformation is governed by stretching as basal drag becomes zero. The same inverse relation is observed along the centre line of Ice Stream D, while most of the ice flow in the onset region of Ice Stream D obeys a positive relation (with $n=1$ ) (Bindschadler and others, 2001). The ice flow in Shirase Glacier catchment obeys a positive relation for $n=3$, which is in agreement with Glen's (non-linear) flow law.

\section{CONGLUSIONS}

We investigated the transition of inland to complex ice flow in the downstream area of the Shirase Glacier catchment, based on force-balance calculations and higher-order numerical ice-sheet modelling. Results of both analyses show that complex flow originates near the MTC, $230 \mathrm{~km}$ upstream from the grounding line of Shirase Glacier. The MTC is characterized by large variations in basal drag, and basal velocity seems as high as (if not higher than) the deformation velocity. Basal drag variations are primarily controlled by normal drag anomalies and (to a lesser extent) by lateral drag. Between this region and the coast, longitudinal normal stresses play a decisive role in the force balance. Driving stresses remain relatively constant with increasing ice speed. Model experiments confirm that complex ice flow, as observed from balance velocities, reaches far inland of the catchment area, which might have implications for the stability of the ice sheet in this area. This also implies that, for modelling studies and ice-dynamical analyses, longitudinal normal stresses do play a role in the force balance of ice sheets, so that large parts of ice sheets can no longer be treated as "zeroth-order". Ice flow and deformation are thus more complex than generally thought.

The fast-flow area is geologically controlled and confined to the "bottleneck" or ice-flow convergence area upstream of the grounding line. It extends only a few tens of kilometres upstream and is characterized by very large normal strain rates. Normal drag also plays a decisive role in the force balance here. An inverse relation between driving stress and ice velocity is observed, both from balancevelocity estimates and from numerical modelling experiments.

\section{AGKNOWLEDGEMENTS}

This paper forms a contribution to the Belgian Research Programme on the Antarctic (Federal Office for Scientific, Technical and Cultural Affairs), contract EV/03/08A. The authors are indebted to R. Greve (Scientific Editor), H. Blatter and an anonymous reviewer for improvements to the manuscript.

\section{REFERENCES}

Bahr, D. B., W. T. Pfeffer and M. F. Meier. 1994. Theoretical limitations to englacial velocity calculations. f. Glaciol., 40(136), 509-518.

Bamber, J. L., D.G. Vaughan and I. Joughin. 2000. Widespread complex 
flow in the interior of the Antarctic ice sheet. Science, 287(5456), 12481250.

Beving ton, P. R. and D. K. Robinson. 1992. Data reduction and error analysis for the physical sciences. Second edition. New York, McGraw-Hill Inc.

Bindschadler, R., J. Bamber and S. Anandakrishnan. 2001. Onset of streaming flow in the Siple Coast region, West Antarctica. In Alley, R.B. and R.A. Bindschadler, eds. TheWest Antarctic ice sheet: behavior and environment. Washington, DC, American Geophysical Union, 123-136. (Antarctic Research Series 77.)

Budd, W. F. and R. C. Warner. 1996. A computer scheme for rapid calculations of balance-flux distributions. Ann. Glaciol., 23, 21-27.

Fujii, Y. 1981. Aerophotographic interpretation of surface features and estimation of ice discharge at the outlet of the Shirase drainage basin, Antarctica. Antarct. Rec., 72, 1-15.

Fujita, S., N. Ikeda, N. Azuma, T. Hondoh and S. Mae. 1991. Numerical estimation of 10,000 years later equilibrium ice sheet profile in the Shirase drainage basin, East Antarctica. Antarct. Rec., 35, 12-29.

Hindmarsh, R. C. A. 2001. Influence of channelling on heating in ice-sheet flows. Geophys. Res. Lett., 28(19), 3681-3684

Hindmarsh, R. C. A. and E. Le Meur. 2001. Dynamical processes involved in the retreat of marine ice sheets. F. Glaciol., 47(157), 271-282. (Erratum: 48(160), 2002, 174.)

Høydal, Ø. A. 1996. A force-balance study of ice flow and basal conditions of Jutulstraumen, Antarctica. 7. Glaciol., 42 (142), 413-425.

Jaeger, J. C. 1969. Elasticity, fracture and flow: with engineering and geological applications. Thirdedition. London, Methuen \& Co. Ltd. and Science Paperbacks.

Liu, H., K. C. Jezek and B. Li. 1999. Development of an Antarctic digital elevation model by integrating cartographic and remotely sensed data: a geographic information system based approach. 7. Geophys. Res., 104(B10), 23,199-23,213.

Lythe, M. B., D. G.Vaughan and BEDMAP Consortium. 2001. BEDMAP: a new ice thickness and subglacial topographic model of Antarctica. $\mathcal{F}$. Geophys. Res., 106(B6), 11,335-11,351.

MacAyeal, D. R. 1992. Irregular oscillations of the West Antarctic ice sheet. Nature, 359(6390), 29-32.

Mae, S. 1979. The basal sliding of a thinning ice sheet, Mizuho Plateau, East Antarctica. 7. Glaciol., 24(90), 53-61.

Mae, S. and R. Naruse. 1978. Possible causes of ice sheet thinning in the Mizuho Plateau. Nature, 273(5660), 291-293.
Mayer, C. and P. Huybrechts. 1999. Ice-dynamic conditions across the grounding zone, Ekströmisen, East Antarctica. f. Glaciol., 45(150), 384 393.

Naruse, R. 1978. Surface ice flow and strain of the ice sheet measured by a triangulation chain in Mizuho Plateau. Nat. Inst. Polar Res. Mem., Special Issue 7, 198-226.

Naruse, R. 1979. Thinning of the ice sheet in Mizuho Plateau, East Antarctica. 7. Glaciol., 24(90), 45-52.

Nishio, F., S. Mae, H. Ohmae, S. Takahashi, M. Nakawo and K. Kawada. 1989. Dynamical behaviour of the ice sheet in Mizuho Plateau, East Antarctica. Proc. NIPR Symp. Polar Meteorol. Glaciol. 2, 97-104.

Pattyn, F. 1996. Numerical modelling of a fast-flowing outlet glacier: experiments with different basal conditions. Ann. Glaciol., 23, 237-246.

Pattyn, F. 2000. Ice-sheet modelling at different spatial resolutions: focus on the grounding zone. Ann. Glaciol., 31, 211-216.

Pattyn, F. 2002. Transient glacier response with a higher-order numerical ice-flow model. 7. Glaciol., 48(162), 467-477.

Pattyn, F. and H. Decleir. 1995. Numerical simulation of Shirase Glacier, East Queen Maud Land, Antarctica. Proc. NIPR Symp. Polar Meteorol. Glaciol. 9, 87-109.

Pattyn, F. and D. Derauw. 2002. Ice-dynamic conditions of Shirase Glacier, Antarctica, inferred from ERS SAR interferometry. 7. Glaciol., 48(163), 559-565.

Payne, A. J. 1995. Limit cycles in the basal thermal regime of ice sheets. $\mathcal{F}$. Geophys. Res., 100(B3), 4249-4263

Raymond, C. F. 2000. Energy balance of ice streams. F. Glaciol., 46(155), 665-674.

Rignot, E. and R. H. Thomas. 2002. Mass balance of polar ice sheets. Science, 297(5586), 1502-1506.

Van derVeen, C. J. 1987. Longitudinal stresses and basal sliding: a comparative study. In Van derVeen, C. J. and J. Oerlemans, eds. Dynamics of the West Antarctic ice sheet. Dordrecht, etc., D. Reidel Publishing Co., 223-248.

Van der Veen, C. J. and I. M. Whillans. 1989. Force budget: I. Theory and numerical methods. f. Glaciol., 35(119), 53-60.

Vaughan, D. G., J. L. Bamber, M. B. Giovinetto, J. Russell and A. P. R. Cooper. 1999. Reassessment of net surface mass balance in Antarctica. 7. Climate, 12(4), 933-946.

Whillans, I. M. and C. J. van der Veen. 1997. The role of lateral drag in the dynamics of Ice Stream B, Antarctica. F. Glaciol., 43(144), 231-237.

MS received 13 January 2003 and accepted in revised form 21 July 2003 